\title{
Progressive Interstitial Renal Fibrosis Due to Chinese Herbs in a Patient with Calcinosis Raynaud Esophageal Sclerodactyly Telangiectasia (CREST) Syndrome
}

\author{
Emi Nishimagi, Yasushi Kawaguchi, Chihiro Terai, Hiroshi KajIYama, Masako Hara and Naoyuki Kamatani
}

\begin{abstract}
A 58-year-old woman with calcinosis Raynaud esophageal sclerodactyly telangiectasia (CREST) syndrome presented with slowly progressive renal dysfunction. She was normotensive with normal plasma renin activity and lacking symptoms of vasculitis. Mild proteinuria was of tubular origin, but serological tests and an absence of sicca symptoms excluded the possibility of Sjögren's syndrome. Light microscopic study of renal biopsy showed interstitial fibrosis with ectasia and degeneration of proximal tubule and lymphocyte infiltration. There were no remarkable changes in the glomeruli. Chromatographic analysis of the Chinese herbs regimen that she had been taking for several years demonstrated aristolochic acid. She was diagnosed as Chinese herbs nephropathy. Therapy with oral prednisolone was markedly effective in improving renal function and anemia. To our knowledge, this is the first report of Chinese herbs nephropathy complicating connective tissue disease. It is important to consider the possibility of Chinese herbs nephropathy when patients treated with Chinese herbs develop renal dysfunction.
\end{abstract}

(Internal Medicine 40: 1059-1063, 2001)

Key words: aristolochic acid, connective tissue disease, prednisolone

\section{Introduction}

Chinese herbs nephropathy (CHN) was first reported in Belgium by Vanherweghem and colleagues in 1993 (1). It is characterized by rapidly progressive fibrosing interstitial nephritis without the involvement of glomerular lesions. Most patients with $\mathrm{CHN}$ in their series had received Chinese herbs as a slimming regimen. The active chemical components of the Chinese herbs were analyzed in detail using high-perfor- mance liquid chromatography (HPLC) to clarify which component in the Chinese herbs caused nephritis (2); it was revealed that the Chinese herbs contained aristolochic acid (AA). AA has been reported to be a chemical that can induce interstitial nephritis. Since then, an increasing number of cases with renal failure due to AA have been reported in Taiwan (3) and Japan (4). We present here a case of CHN in a patient with calcinosis Raynaud esophageal sclerodactyly telangiectasia (CREST) syndrome and discuss the pathogenesis and treatment of CHN.

\section{Case Report}

A 58-year-old woman with scleroderma was admitted to Aoyama Hospital, Tokyo Women's Medical University because of dyspnea on effort and renal dysfunction. She had noticed Raynaud's phenomenon at the age of 40. In 1985, she had started taking several kinds of Chinese herbs which were obtained from a pharmacy for edema of her hands and fingers. In 1986, she began attending an out-patient clinic for Chinese herbal medicine. While she continued to go to the clinic until 1999 , the herbal formula was changed several times. She consulted our hospital in 1993 at 51 years of age, because of dyspnea on effort and palpitation. She was diagnosed as CREST syndrome, due to calcinosis of her finger tips, Raynaud's phenomenon, esophageal reflux, sclerodactylia, telangiectasia, and positive anti-centromere antibody. She had normal renal function from her first examination until June 1997, then serum creatinine levels started to increase gradually.

On admission in 1999, physical examination revealed a 58 $\mathrm{kg}$ woman with blood pressure of $140 / 78 \mathrm{mmHg}$, and pulse rate $83 / \mathrm{min}$. She had ankyloglossia, tongue-tie, telangiectasia of the chest and shoulders, sclerodactylia, nail fold thrombi, and calcinosis of her fingers and toes. She was afebrile and there was no edema. Urinalysis did not show albuminuria or hematuria. Investigations showed a hemoglobin of $10.9 \mathrm{~g} / \mathrm{dl}$ with a normal white blood cell and platelet count. Blood chemistries revealed blood urea nitrogen $24 \mathrm{mg} / \mathrm{dl}$, creatinine 2.1

From Institute of Rheumatology and Aoyama Hospital, Tokyo Women's Medical University School of Medicine, Tokyo

Received for publication November 12, 2000; Accepted for publication June 14, 2001

Reprint requests should be addressed to Dr. Yasushi Kawaguchi, Institute of Rheumatology, Tokyo Women's Medical University, 10-22 Kawada-cho, Shinjukuku, Tokyo 162-0054 
$\mathrm{mg} / \mathrm{dl}$, total protein $7.6 \mathrm{~g} / \mathrm{dl}$, AST $23 \mathrm{IU} / l$, ALT $22 \mathrm{IU} / l, \mathrm{LDH}$ $278 \mathrm{IU} / l$, glucose $115 \mathrm{mg} / \mathrm{dl}$, sodium $142 \mathrm{mEq} / l$, potassium $4.0 \mathrm{mEq} / l$, chloride $107 \mathrm{mEq} / l$. Antinuclear antibody $(1,280 \times$, homogeneous and discrete-speckled pattern) and anti-centromere antibody $(147 \mathrm{IU} / \mathrm{ml}$, determined by enzyme immunoassay) were positive. The other autoantibodies including antitopoisomerase I, anti-SSA, anti-SSB, anti-RNP and anti-Sm antibodies were negative. Schirmer and gum tests were negative. The patient was evaluated as not having the complication of Sjögren's syndrome. Plasma renin activity and angiotensin II were normal at $1.5 \mathrm{ng} / \mathrm{ml} / \mathrm{h}$ and $24 \mathrm{mg} / \mathrm{dl}$, respectively. Urine volume was $1,900 \mathrm{ml} /$ day and 24 -hour creatinine clearance was $22 \mathrm{ml} / \mathrm{min}$. A 24-hour urine collection contained $450 \mathrm{mg}$ of protein despite a negative albustix test, thereby suggesting that proteinuria was derived from tubular damage. Urinary $\beta 2$ microglobulin was $16,746 \mu \mathrm{g} / \mathrm{l}$ (normal range: $<200$ ), and NAG was $6.1 \mathrm{U} / l$ (normal range: $\leq 11.5$ ). Ultrasonography revealed mildly atrophic kidneys. Renal biopsy contained a total of 13 glomeruli, of which 3 were totally sclerosed but other glomeruli were normal. In the interstitium, ectasia and degeneration of the proximal tubular cells and severe fibrotic changes with lymphocyte infiltration were seen focally (Fig. 1). There was no evidence of vascular involvement suggesting angiitis or scleroderma renal crisis (SRC). Immuno-fluorescence staining was negative.

Considering the prolonged clinical course and the laboratory and pathological findings, it was unlikely that SRC or angiitis was the cause of renal dysfunction. These results prompted us to assess the medicines this patient took as a cause of interstitial renal failure. After reviewing all the medicines she took, Chinese herbs were strongly suspected as the cause of renal failure. Recently, it has been reported that interstitial renal failure is induced by aristolochic acid contained in Chinese herbs. Since she had been taking a mixture of several Chinese herbs included in a single formula, we analyzed this Chinese herbs mixture. AA-I which is known to be one of the causative agents
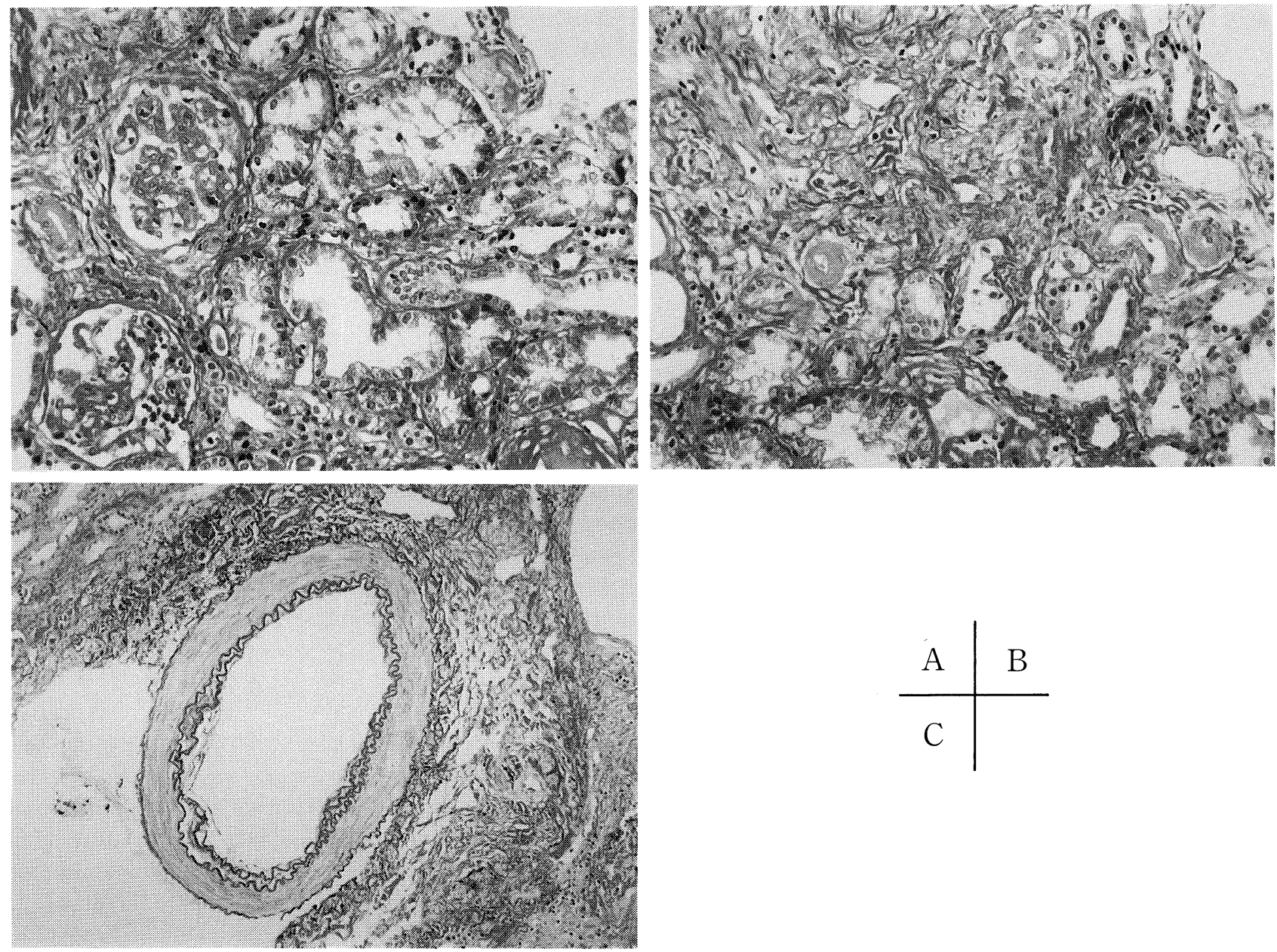

Figure 1. Light microscopic observation of renal biopsy specimen (A) Glomeruli were normal. (Masson's staining, $\times 200)$. (B) Ectasia and degeneration of the proximal tubular cells and severe fibrotic changes with lymphocyte infiltration were seen in the interstitium. (Masson's staining, $\times \mathbf{2 0 0}$ ). (C) There was no thickening or degeneration of the intima or media of arterioles. There was no thrombus in the vascular regions (Elastica-Van Gieson's staining, $\times 100$ ). 

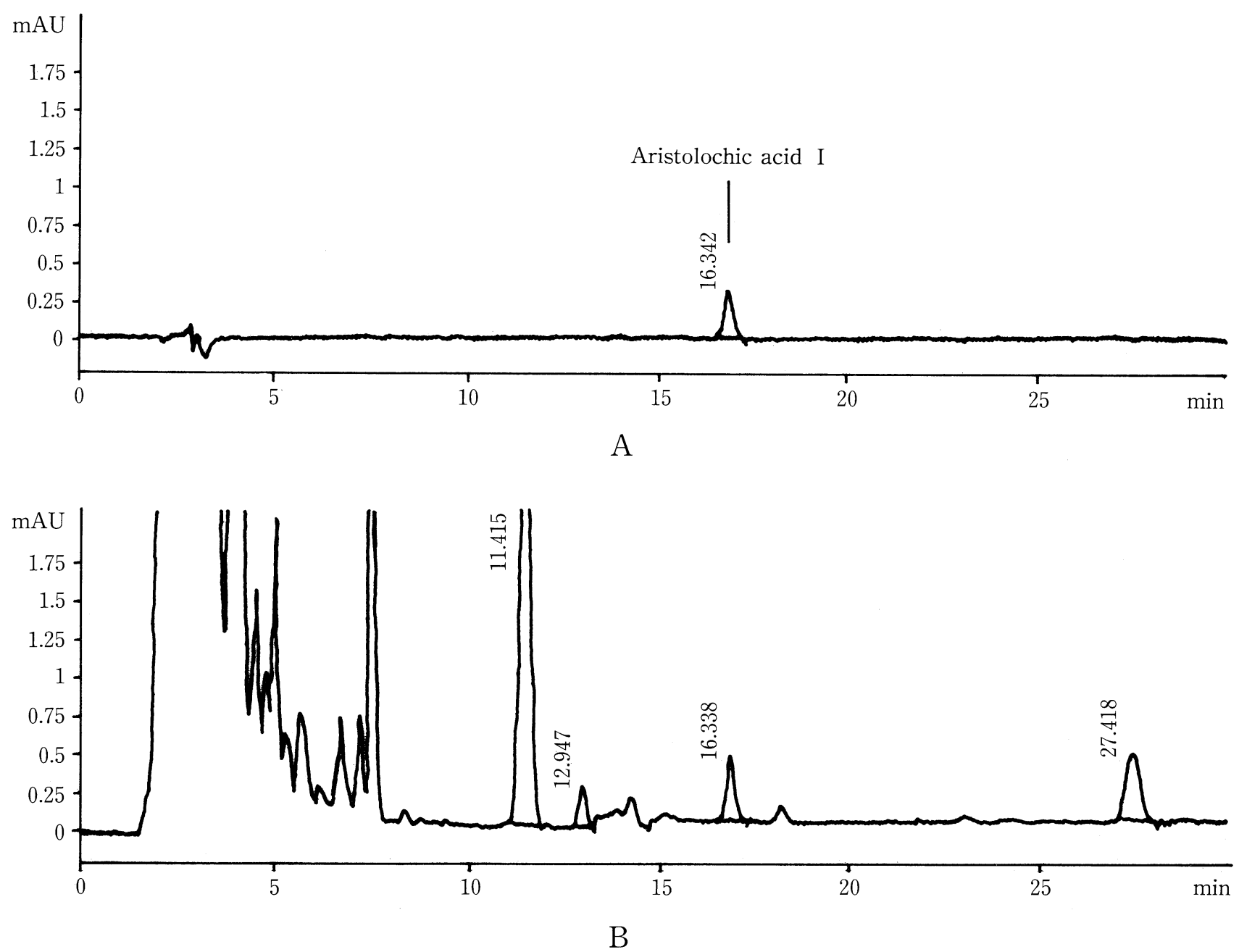

Figure 2. HPLC trace of Chinese herbal formula. (A) Analysis of aristolochic acid I (AA-I). (B) Analysis of Chinese herbal formula taken in this case. Trace shows presence of AA-I in Chinese herbal formula.

of CHN was detected by HPLC (Fig. 2). Renal dysfunction and anemia had progressed gradually since February 1997, and continued to progress even after discontinuing all of the herbal medicines in September 1999. In the clinical course shown in Fig. 3, renal function and anemia had deteriorated further (creatinine: $2.1 \mathrm{mg} / \mathrm{dl}, \mathrm{Hb}: 10.1 \mathrm{mg} / \mathrm{dl}$ ) in February 2000 . Blood pressure in this case was stable throughout the observation. The administration of oral prednisolone ( $30 \mathrm{mg} /$ day) was started in March to treat CHN. The patient responded to steroid therapy and symptoms were improved (creatinine $1.4 \mathrm{mg} / \mathrm{dl}, \mathrm{Hb} 12.5$ $\mathrm{g} / \mathrm{dl})$.

\section{Discussion}

Renal dysfunction in the present case was diagnosed as $\mathrm{CHN}$ by renal histology and the presence of AA-I in the Chinese herbs the patient took. In general, the pathological examination of CHN is reported to reveal diffuse interstitial hypocellular fibrosis and tubular atrophy without any prominent glomerular disorder (1), which are similar findings to those of our case. AA detected in the Chinese herbs formula is reported to be a causative agent of renal interstitial fibrosis (2). AA is usually contained in the Chinese herb "Kanmokutsu". The present patient received "Toki-shigyaku-ka-gosyuyu-syokyo-to", one of the traditional prescriptions of herbal mixtures. In Japan, the prescription contains "Mokutsu", which is Akebia quinata in Latin, and usually does not contain AAs. However, when "Tokishigyaku-ka-gosyuyu-syokyo-to" is prepared in China, it often contains "Kanmokutsu" (aristolochia manshuriensis) in place of "Mokutsu" and this herb contains AAs (5). In the present case, the patient's family doctor imported the Chinese herbs directly from China. We considered that "Kanmokutsu" might have been included in the "Toki-shigyaku-ka-gosyuyusyokyo-to" mixture made in China.

In AAs, nine analogs from plants are well known. These are I (A), II, III, IV, C (III a), D (IV a) and E (6). AA-I in particular is reported to be a potent cause of gene mutation (6), suggesting that the genotoxic activity would play a crucial role in the 

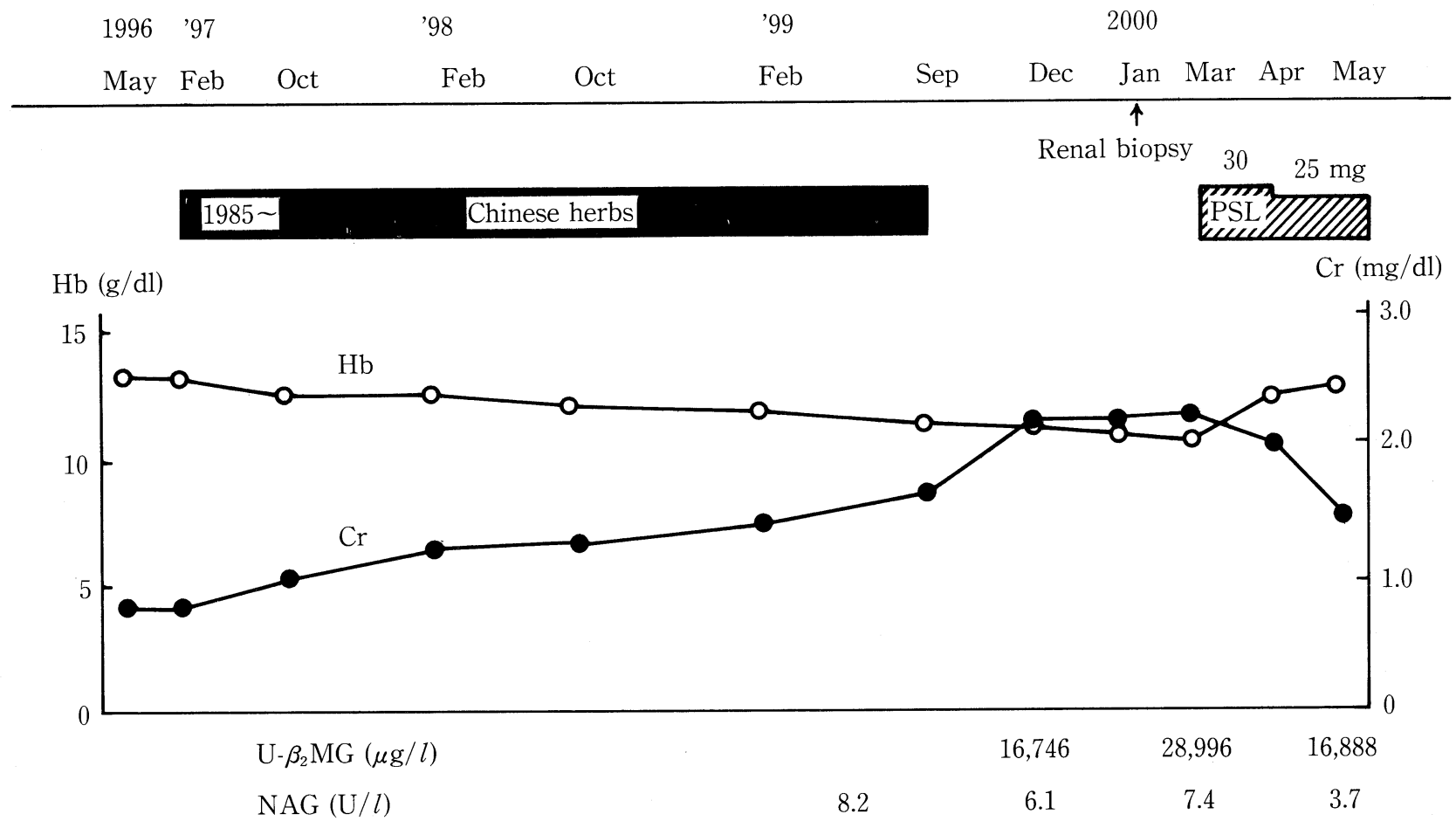

Figure 3. Clinical course.

pathogenesis of $\mathrm{CHN}$.

Most reported patients with $\mathrm{CHN}$ show rapid deterioration of renal function despite discontinuation of the herbal medications. Schmeiser and colleagues demonstrated the presence of AA-derived DNA adducts in the renal tissue of patients with CHN (7) and suggested that DNA mutation was responsible for the renal fibrotic process and urothelial cancers observed in CHN (3). In the present case renal function showed progressive deterioration despite discontinuation of the herbal treatment as is typical of most patients with CHN. We suggested that mutations in the DNA level might be the reason why the progressive fibrotic changes persisted even though the exposure to AAs had stopped.
Carcinomas of the urinary tract are described in CHN with increasing frequency (8). Cosyns and colleagues studied nineteen kidneys and ureters from $10 \mathrm{CHN}$ patients and demonstrated an overexpression of mutated p53 (a tumor suppressor gene) in all carcinoma in situ and papillary transitional cell carcinoma specimens examined (9). There was no evidence of such malignancy in this case at the time of the study. However, it is important to be aware of this evidence and strict observation must be continued.

The standard treatment of $\mathrm{CHN}$ has not yet been established. In the present case, oral prednisolone was given and her renal function and anemia showed improvement. Vanherweghem and colleagues reported the efficacy of corticosteroid therapy in

Table 1. Previous Case Reports of Chinese Herbs Nephropathy (CHN)

\begin{tabular}{|c|c|c|c|c|c|}
\hline Reporters & Published year & Number of cases & $\begin{array}{c}\text { Materials } \\
\text { causing CHN }\end{array}$ & Therapy & Prognosis \\
\hline Vanherweghem et al & 1993 & 35 & Aristolochic acid & $\begin{array}{l}\text { C- } 23 \text { cases } \\
\text { CS- } 12 \text { cases }\end{array}$ & $\begin{array}{l}\text { HD- } 16 \text { cases } \\
\text { HD- } 2 \text { cases }\end{array}$ \\
\hline Tanaka et al & 1997 & 1 & Aristolochic acid & C-1 case & \\
\hline Yang et al & 2000 & 12 & $\begin{array}{c}\text { no analysis of } \\
\text { herbal medication }\end{array}$ & C- 12 cases & HD-7 cases \\
\hline Tanaka et al & 2000 & 2 & Aristolochic acid & C- 2 cases & \\
\hline
\end{tabular}

C: Cessation of herbal medications, CS: Corticosteroids, HD: Hemodialysis. 


\section{Chinese Herbs Nephropathy with CREST}

1996 (10). They compared a steroid-treated group $(n=12)$ to a control group $(n=23)$. Renal function was better preserved in the steroid-treated group at one year $(\mathrm{p}=0.001)$. Only two of the 12 patients in the steroid-treated group required dialysis at one year compared with 16 of 23 patients in the control group. Therefore, Vanherweghem and colleagues suggested that steroid induces interference with $\mathrm{T}$ lymphocyte functions and the synthesis of chemical mediators might lead to suppression of production and proliferation of the extracellular matrix as a possible mechanism. They gave prednisolone at a dose of 1 $\mathrm{mg} / \mathrm{kg}$ weight as an initial dose. Since our case was complicated by CREST syndrome, high-dose steroid therapy was considered a risk factor for scleroderma renal crisis. Therefore, we decided to administer $30 \mathrm{mg} /$ day which was much less than the dose used in the previous study. The effective dosage of prednisolone for patients with $\mathrm{CHN}$ has not yet been established. Comparisons of therapy and prognosis of several reports are shown in Table 1. To our knowledge, there were few reports of successful treatment of $\mathrm{CHN}$ that improved the prognosis. In this report, we demonstrated that the administration of corticosteroids may have improved the renal function of this CHN case, suggesting that steroid-therapy would be a good strategy for CHN. Further investigation of the treatment including corticosteroids for $\mathrm{CHN}$ must be undertaken in the future.

In this case, a diuretic Chinese herbal formula was prescribed for the edematous phase of skin thickening in CREST syndrome. In some cases of connective tissue diseases, especially slowly progressive cases, it is difficult to diagnose the disease from early symptoms. In fact, it is not rare for patients with connective tissue diseases taking Chinese herbal medications or some kinds of herbal tea since Chinese herbs are thought to be safe, and to have a lower incidence of adverse effects. The present case should serve to warn physicians of the importance of considering Chinese herbs as one of the possible causal factors promoting renal failure in patients with connective tissue diseases.
Acknowledgement: The authors appreciate Dr. Masahiko Watanabe (Tsumura Co.) for HPLC analysis of aristolochic acid.

\section{References}

1) Vanherweghem JL, Depierreux M, Tielemans C, et al. Rapidly progressive interstitial renal fibrosis in young women: association with slimming regimen including Chinese herbs. Lancet 341: 387-391, 1993.

2) Stiborova M, Frei E, Breuer A, Bieler CA, Schmeiser HH. Aristolactam I a metabolite of aristolochic acid I upon activation forms an adduct found in DNA of patients with Chinese herbs nephropathy. Exp toxicol Pathol 51 (4-5): 421-427, 1999.

3) Yang C-S, Lin C-H, Chang S-H, Hsu H-C. Rapidly progressive fibrosing interstitial nephritis associated with Chinese herbal drugs. Am J Kidney Dis 35: 313-318, 2000.

4) Tanaka A, Nishida R, Sawai K, et al. Traditional remedy-induced Chinese herbs nephropathy showing rapid detoriation of renal function. Jpn J Nephrol 39: 794-797, 1997.

5) Tanaka A, Nishida R, Maeda K, Sugawara A, Kuwahara T. Chinese herb nephropathy in Japan presents adult-onset Fanconi syndrome: could diffrent components of aristolochic acids cause a different type of Chinese herbs nephropathy? Clin Nephrol 53: 301-306, 2000.

6) Maier P, Schawalder H, Weibel B. Low oxygen tension, as found in tissues in vivo, alters the mutagenic activity of aristolochic acid I and II in primary fibroblast-like rat cells in vitro. Environ Mol Mutagen 10: 275284, 1987.

7) Schmeiser HH, Bieler CA, Wiessler M, van Ypersele de Strihou C, Cosyns JP. Detection of DNA adducts formed by aristolochic acid in renal tissue from patients with Chinese herbs nephropathy. Cancer Res 56: 20252028, 1996.

8) Nortier JL, Martinez MCM, Schmeiser HH, et al. Urothelial carcinoma associated with the use of a Chinese herb (Aristolochia fangchi). N Engl J Med 342: 1686-1692, 2000.

9) Cosyns JP, Jadoul M, Squifflet JP, Wese FX, van Ypersele de Strihou C. Urothelial lesions in Chinese-herb nephropathy. Am J Kidney Dis 33: 1011-1017, 1999.

10) Vanherweghem JL, Abramowicz D, Tielemans C, Depierreux M. Effects of steroids on the progression of renal failure in chronic interstitial renal fibrosis: A pilot study in Chinese herbs nephropathy. Am J Kidney Dis 27: 209-215, 1996. 